\title{
Functional and Psychosocial Characteristics of Elderly in Federation of Bosnia and Herzegovina
}

\author{
Šarić Edina ${ }^{1}$, Mehmedinović Senad $^{1, *}$, Bratovčić Vesna ${ }^{1}$ and Ahmetović Sadik ${ }^{2}$ \\ ${ }^{1}$ Faculty of Education and Rehabilitation, University of Tuzla, Bosnia and Herzegovina \\ ${ }^{2}$ Council of Ministers of Bosnia and Herzegovina, Bosnia and Herzegovina
}

\begin{abstract}
The aim of the research was to identify psychosocial factors and functional characteristics of the elderly. The survey covered a stratified sample of 60 patients with advanced age, both sexes, living in a family environment. In order to assess functional and psychosocial characteristics of older persons were used: Barthel index test, self-assessment scale for depression, self-esteem Rosenberg scale, PD Questionnaire / Form A scale for assessing the degree of social support, as well as Structured questionnaire of personal data which we collected data on gender, age, marital status, number of children, diagnosis, and self-economic situation. Data analysis was performed using parametric and nonparametric statistics. To determine the latent space of applied variables factor analysis was used. Based on the results of the study there are four (4) factors: Factor of somatopsychic dimensions of existential anxiety, Factor of socioeconomic status, Factor of social status and Health status factor.
\end{abstract}

Keywords: Elderly, functional and psychosocial characteristics.

\section{INTRODUCTION}

Functional ability connotes the ability of an individual to conduct everything what is necessary so as to ensure adequate quality of a daily living, and it includes biological, psychological and social functioning [1]. Tomek-Roksandić et al. [2] write that functional ability connotes the ability which a person is using for executing daily life activities, but also those abilities which could be useful so as to remunerate decrease of other abilities. Activities which elderly people can individually execute, or which they think they can execute, are a useful indicator of a health status of a person and his or her needs for help in case of weakening of ability of the self-care. Thereby, the ability of an elderly person to independently function in his or her own home is of the utmost importance. Functional ability is a critical indicator of life and health quality among elderly people, sometimes even more important than the presence of some illness. The weakening of functional and cognitive ability are usually the best predictors of mortality i.e. the need for institutional care of the elderly. Real extent of health condition is made of, not only the presence of illness, but also of the level of functional inability. DespotLučanin [3] indicate that persons see themselves as ill firstly when illness obstructs activities of their daily living i.e. ability of self-care and house-keeping. Kaplan et al. [4] on a sample of 356 persons of third life age have examined the connection of demographic, health,

*Address correspondence to this author at the Faculty of Education and Rehabilitation, University of Tuzla, Univerzitetska 1, 75000 Tuzla, Bosnia and Herzegovina; Tel: 0038762901229; Fax: 0038735320660;

E-mail: senad.mehmedinovic@gmail.com psychological and social factors with changes in functional abilities.

Out of demographic factors, important predictors of functional changes were age and low income. Important health predictors were self-evaluation of health, health behaviour, one or more chronic diseases, previous stroke or previous heart attack. Important psychological predictors were depression and the feeling of personal health control, and social predictors were marital status and social support. Strawbridge et al. [5] have, on longitudinal study which lasted for 6 years and included 365 persons older than 65 years of age, examined the impact of gender on changes in functional abilities. Their results have shown that income, education and marital status are predictors of functional change for men, and the feeling of personal health control, for women. Newer research has also shown that changes in functional abilities systematically vary by gender, education and income. Idler and Kasl [6] have examined the longitudinal predictability of self-evaluation of health for future functional ability of elderly with relation to their age, gender and direction of ability change (decline or recovery). Achieved research results have shown connection of self-evaluation of health with functional ability. Namely, research results have shown that functional ability, with the examinees who have estimated their health as bad in initial examination, has, after 6 years declined for 2,5 times, in relation to examinees who have estimated their health as excellent. Fiedler and Peres [7] research results have shown connection between poor functional capacity and factors such as greater chronological age, 
affiliation to female gender and negative self-perception of socio-economic status. Hence, numerous researches have shown that there is connection between functional and psychosocial characteristics of persons of third life age.

In accordance with that, main aim of this research was to determine connection of mentioned factors on population of third life age in Federation of Bosnia and Herzegovina, as well as to determine which of the factors determines that interconnectedness the most.

\section{MATERIAL AND METHODS}

The research included stratified sample of examinees of third life age, who live in family surroundings. The sample consisted of examinees from three different localities of Federation of Bosnia and Herzegovina. The sample of examinees was formed through register lists of persons of third life age at the Institute for health insurance. After the examinees were randomly chosen into stratums, a telephone call was made for the aim of representing the research as well as for the aim of gaining consent of the examinees for survey. All examinees agreed to participate in the research. The sample was made out of 60 examinees of both sexes, 20 from three different regions of Federation of Bosnia and Herzegovina. The sample was formed of the examinees who have achieved 27 and more points on Mini Mental State Examination [8], i.e. examinees who do not have cognitive deficit. Out of total number of examinees, $60 \%(\mathrm{~N}=36)$ are women, $40 \%(\mathrm{~N}=24)$ are men. Average chronological age for women is $74 \pm 7,18$, and age span is from $65-93$. Average chronological age for men is $75 \pm 6,18$, and age span is from 68-92. Research was done at own home of every examinee and was done individually in duration of 50-90 minutes per examinee.

For the needs of this research, following measuring instruments were used:

Barthel Index of Activity of Daily Living (BIT) represents a scale for measuring activities of daily life and mobility [9].

Activities of personal hygiene, bathing and movement with trolley are appraised from 0-5., toilet, climbing up stairs, getting dressed, stool control and voiding control are appraised with $0,2,5,8$ and 10 , while the transfer chair-bed and movement are appraised with $0,3,8,12$ and 15 points. Score of the points moves from 0 to 100 .
Self rating depression scale (Self Rating Depression Scale - SDS) was constructed by Zung in 1965 [10]. Scale contains 20 particles, and for each assertion one must give answer on scale of four levels. As per numerous works where SDS was used, it is ascertained that patients with mild or moderate depression have results $50-59$, those with moderate to strong depression $60-69$, and patients with strong depression more than 70 points.

Rosenberg self-esteem scale (ROS) contains 10 particles to which answers are given on Likert's type of scale with four levels (from 1 to 4 ). Before summarizing the evaluations, it was necessary to inversely mark some of the assertions which indicate lack of selfesteem. Higher result marks more self-esteem, and results move in range from 10 to 40 .

Questionnaire PD/form A [11]. Questionnaire is intended for revealing of the cooping mechanism on basis of controlled variables. Through appliance of this instrument, a dimension of self-evaluation of the "good" feeling is comprised. The examinees were told to state thoughts and feelings which dominate in their experience of the self, when they say "I feel good". This variable is interpreted with the help of number of induced dominant thoughts during self-evaluation, and defined by the examinees themselves. Also, a modified visual-analogue self-evaluation scale from $0-100$ is used on which examinees determined the value when they say "I feel good".

Scale for evaluation of social support level [12]. This scale consists of 8 particles, and the examinee should estimate to what extent do close persons "give encouragement", "give useful information", "give direct help" and similar to him or her on the scale of 4 levels (never, sometimes, often, always).

Structured questionnaire of personal data consists of questions through which data on sex, age, marital status, number of children, illness diagnosis, selfevaluation of material state on scale of five, selfevaluation of health condition on scale of five levels and socioeconomic status (type of household, number of members of collective household, number of actively employed members of collective household, total material household income) are gathered.

Research data were processed through method of parametric and non-parametric statistics. For statistical data processing, a computer statistical program SPSS for WINDOWS 16.0. was used. For determining latent 
space of applicable variables of functional and psychosocial characteristics of persons of third age, a method of factor analysis was used.

\section{RESULTS}

In order to determine correlation between functional status and psychosocial characteristics measures of correlation were done by multiple correlation where the system of several dependant variables was chosen in relation the system of independent variables which is the subject of this research. By analysing the matrix of intercorrelations, it can be noticed that diagnosis of chronic ailment with the absence of disease has relatively high correlation $(0,59)$.

Then, relatively high correlation belongs to variables "Disability degree" and "Amount of disability reimbursement and allowance for home care and assistance" $(0,61)$, and which is also normal to expect, that persons with higher percentage of disability will have higher reimbursement and also higher allowance for home care and assistance. Then, relatively high but negative correlations between "Disability degree" and "Barthel Index of Activity of Daily Living" $(-0,46)$ and "Index Barthel text results per categories" $(-0,53)$ can be seen, which points out to the fact that higher degree of estimated disability affects lower independence and autonomy in daily life activities, which is also logical for this research. Slightly less positive correlation can be seen between this variable and "Self-evaluation depression scale results" $(0,43)$, which points out to the fact that disability degree has causal connection with psychological factors which influence occurrence of depressive symptoms with examinees. Amount of pension as variable has negative correlation with gender $(-0,34)$, which points out to the fact that persons of female sex from this sample, in most cases, have never been employed, and therefore have not accomplished their own pension. The amount of disability reimbursement has slight correlation with selfevaluation of health condition $(-0,33)$ and self-esteem ($0,34)$, which points out to the fact that persons who have lower income than disability reimbursement also have greater evaluation of self-esteem. Also, the amount of social assistance has moderate correlation with "Barthel Index of Activity of Daily Living" $(-0,41)$, which points out to the fact that mostly those persons who are more dependant on daily life activities are users of social assistance.

Very high expected correlation was shown by variables "Barthel Index of Activity of Daily Living" and
"Index Barthel text results per categories" $(0,89)$, but also variable "Barthel Index of Activity of Daily Living" has high negative correlation $(-0,45)$ with "Selfevaluation depression scale results", which we explain in a way that persons who are more dependant on daily life activities show greater symptoms of depression. "Barthel Index of Activity of Daily Living" accomplishes relatively high correlation with variable "Results on Rosenberg self-esteem scale" $(-0,43)$, which points out to the fact that persons who are more independent in daily life activities have more self-esteem. Variable "Self-evaluation depression scale results" has negative correlation with variable "Self-evaluation of health condition" $(-0,44)$ which is explained through the fact that examinees who show greater depression symptoms are weaker in estimating their health condition; and also, this variable has negative correlations with variables "Results on Rosenberg selfesteem scale" $(-0,56)$ and "Range of self-evaluation of the "good" feeling on visual analogue scale" $(-0,33)$, which points out to the fact that more expressed symptoms of depression reflects weaker self-esteem on Rosenberg self-esteem scale, but also on Visual analogue scale, the feeling of "good" is estimated with lower values. Variable "Self-evaluation of health condition" has positive correlation with variable "Selfevaluation of material state" $(0,33)$ which points out to the fact that good self-evaluation of material status with the examinees implies better self-evaluation of health condition and also self-esteem which is shown by connection of coefficient values $(0,51)$. Also, this variable accomplishes high correlation with "Range of self-evaluation of the "good" feeling on visual analogue scale" $(0,58)$ which points out to the fact that persons who are better in estimating their health condition also have greater self-evaluation of good feeling on applied variable.

However, variable "Self-evaluation of health condition" has negative correlation with variable "Ucla Lonelines Scale" $(-0,33)$. The values of "Ucla Lonelines Scale" in relevant measurement go in negative direction and it can be ascertained that persons who evaluate their health condition better have lower feeling of Ioneliness. Variable "Self-evaluation of material state" has positive correlation with "Ucla Lonelines Scale" $(0,36)$, but also negative correlation with "Range of self-evaluation of the "good" feeling on visual analogue scale" $(-0,37)$. This points out to the fact that persons who estimate their material status worse have greater level of loneliness and poorly self-evaluate the value when they say I feel "good" on visual analogue 
scale. Variable "Results on Rosenberg self-esteem scale" has negative correlation with "Self-evaluation depression scale results" $(-0,51)$, but has positive correlation with "Self-evaluation of material state" $(0,36)$, and negative correlation with "Ucla Lonelines Scale" $(-0,60)$, then positive correlation with "Range of self-evaluation of the "good" feeling on visual analogue scale" $(0,40)$ and "Number of dominant thoughts for experience of the self for variable good" $(0,34)$. This points out to the fact that persons who have greater feeling of self-esteem show less symptoms of depression, but also feel lonelier. Better self-evaluation of self-esteem increases the evaluation of feeling good, but also of the number of dominant thoughts with this feeling. Variable "Ucla Lonelines Scale" has moderate negative correlation with "Results on scale of social support" $(-0,49)$. Persons who evaluate lower level of loneliness evaluate lower support of environment. Variable "Range of self-evaluation of the "good" feeling on visual analogue scale" has negative correlation with "Health/disease" $(-0,40)$. The more the examinees evaluate greater feeling of good, the higher is the possibility that they will be in the category of those who do not have registered chronic diseases.

Variable "Number of collective household members" very highly positively correlates with variables "Household type" $(0,71)$, "Number of actively employed household members" $(0,73)$ and "Total material household incomes" $(0,87)$.

Such correlation points out to the fact that the greater the number of members of household the more typical is the community where the number of actively employed members grows and therefore total material income in the household also grows.

Explorative factor analysis was applied with the aim of determining the factors which determine mutual connection of functional and psychosocial characteristics. Two models were applied, common factors model and component model. For the final analysis of latent variables, variables which have highest correlations entered and those variables are: "Health status", "Invalidity level", "Index Barthel test results", "Index Barthel text results per categories", "Self-evaluation depression scale results", "Selfevaluation of material state", "Self-evaluation of health condition", "Results on Rosenberg self-esteem scale", "Range of self-evaluation of the "good" feeling on visual analogue scale", "Number of dominant thoughts for experience of the self for variable good", "Number of collective household members", "Household type", "Number of actively employed household members", "Total material household incomes", and "Results on scale of social support". Kaiser-Meyer-Olkin (KMO) and Barlet test were calculated for suitability of matrix in interpretation, and it is determined that this coefficient amounts to 0,736 , which, per values of this matrix coefficient, is very suitable for latent analysis.

\section{DISTINCTIVE VALUES OF ISOLATED FACTORS}

Table 1 shows how much of collective variability explains each individual factor. As per Guttman-Kaiser criteria, it can be affirmed that 4 attributive values, which together deplete $25,01 \%$ of whole measuring variability system, are important, out of 15 variables which enter analysis. First attributive value or first main component depletes $3,75 \%$ of collective variance of system, and following attributive values deplete all smaller collective variances so that the last factor (component) has extracted attributive value of $1,40 \%$ of collective variance, which represents the least important factor for interpretation of latent space which defines functional and psychosocial status of persons of third life age.

Since the first factor has the largest amount of collective variance which it explains, it also has the largest importance for planned initial intervention of somatopedic treatments of persons of third life age, and which persons are in need of that treatment.

Table 2 gives insight into coefficients of parallel and orthogonal projections of variables on isolated factors.

Table 1: Distinctive Values (Lambda), Cumulative Variance (Matrix Percentage of Intercorrelation of Variables) and Collective Variance Percentage

\begin{tabular}{|c|c|c|c|}
\hline Factor & Distinctive values & Cumulative variance & Collective variance percentage \\
\hline \hline 1 & 3.75 & 25.01 & 25.01 \\
\hline 2 & 3.50 & 48.34 & 23.33 \\
\hline 3 & 1.96 & 61.34 & 12.10 \\
\hline 4 & 1.40 & 70.71 & 9.37 \\
\hline
\end{tabular}


Table 2: Isolated Components

\begin{tabular}{|c|c|c|}
\hline Isolated first main component & PAP & ORP \\
\hline Dependence in daily life activities & -.93 & -.91 \\
\hline Daily life activities & -.90 & -.89 \\
\hline Invalidity level & .73 & .73 \\
\hline Depression & .66 & .71 \\
\hline \multicolumn{3}{|l|}{ Isolated second main component } \\
\hline Total material household income & .95 & .96 \\
\hline Number of actively employed household members & .91 & .91 \\
\hline Number of collective household members & .90 & .89 \\
\hline Household type & .87 & .87 \\
\hline \multicolumn{3}{|l|}{ Isolated third main component } \\
\hline Self-evaluation of material state & .81 & .78 \\
\hline Self-evaluation of social support & .62 & .65 \\
\hline Number of dominant thoughts & .60 & .63 \\
\hline Self-esteem & .56 & .61 \\
\hline \multicolumn{3}{|l|}{ Isolated fourth main component } \\
\hline Presence of chronic disease & .82 & .76 \\
\hline Self-evaluation of the good feeling & -.80 & -.83 \\
\hline Self-evaluation of health condition & -.59 & -.70 \\
\hline
\end{tabular}

First isolated factor, as per their parallel and orthogonal projections, was entered by variables "Dependence on daily life activities" $(-0,93 ;-0,91)$, "Daily life activities" ($0,90 ;-0,89)$, "Invalidity level" $(0,73 ; 0,73)$ and "Expression of depressive symptomatology" $(0,66$; $0,71)$. The results of parallel and orthogonal projections on isolated variables point out that the persons of third life age from the examined sample have greater level of disability and at the same time show more expressed depression symptoms, which reflects on increased dependence on others in executing daily life activities and declined daily life activity. In relation to condensation of variables, this factor can be named Somatopsychological dimension of existential anxiety factor.

Through insight into second isolated factor, very high and positive coefficients of parallel projections in isolated variables, which constitute this factor, can be noticed. The largest coefficients of parallel and orthogonal projections were shown by variables which relate to material income and the number of actively employed members, but also other variables point out to number of all household members, which manifested itself through variable "Household type", and which means that household type significantly determines the first three isolated variables. Since this is the case of variables which determine socio-economic status, this factor was named Socio-economic status factor.

The third factor in this research is defined also through four variables which have positive PAP and ORP, and those variables are: "Self-evaluation of material status", "Self-evaluation of social support", "Number of dominant thoughts" and "Self-respect". This factor can be named Psychosocial status factor. Largest saturation on fourth factor has variable "Presence of chronic disease", and this factor can be named Health condition factor.

\section{DISCUSSION}

On basis of achieved research results, four factors of functional and psychosocial status of persons of third life age are isolated. The first factor of somatopsychological dimension of existential anxiety is most important predictor of preventive somatopedic / somato-therapy intervention. Results achieved on this factor are in favor of longitudinal research [13-17], whose results have shown that invalidity leads to increased depression, as well as in favor of research of Alexopoulos et al. [18], which achieved that depression is related to invalidity level of persons of third life age. 
Such results clearly point out to the causal connection of functional and psychosocial status of persons of third life age in Bosnia and Herzegovina, and they can help with creation of complement supportive therapy programs, which are orientated towards improvement of life quality of this population of people. Defining of the second factor of socioeconomic status, points out to the fact that most people of third life age in Bosnia and Herzegovina have no income whatsoever from formal earnings (employment or self-employment), pension and invalidity emolument, social security emoluments and other emoluments, and that in most cases they live alone or with a spouse.

These results are in line with socio-economic index of Federal statistics institute of Federation of Bosnia and Herzegovina, which show that persons of third life age are socially excluded, due to inadequate social care system and that they are most imperiled household category. In order to enable social engagement of mentioned population, it is necessary to open gerontological non-institutional daily centers, and which are in Tuzla canton non-existent, whose aim would be ensuring different help and support systems, taking into consideration their specific needs.

Justifiability for appointing the third factor of psychosocial status is pointed out by variables of selfestimation of material status and social support, and psychological component of this factor is expressed in variable of number of dominant thoughts related with thoughts and feelings which dominate in their experience of the self when they say I feel "good" and self-respect.

This points out to the fact that psychological dimensions and experience of the self, which are expressed through number of dominant thoughts, and self-respect, are in great correlation with self-estimation of own material status and social support, and which is also pointed out by saturation of psychological variables on this factor. Results achieved on fourth factor of health condition are in favor of research by Knurowski et al. [19] who have, through factor analysis, identified most important dimension of health among older people, and who have achieved, just like in this research, isolated fourth, final main component, where the presence of chronic disease determines the remaining two variables. Also, the results are in favor of research [20-24] who achieved that the number of chronic disease is one of the clearest determinants of health self-evaluation.

\section{CONCLUSION}

On basis of results of conducted research, multidimensional connection of influence of psychosocial factors on changes in functional status of persons of third life age is affirmed. On basis of statistical informatics processing of original data, 4 factors are defined: "Somatopsychological dimension of existential anxiety factor", "Socio-economic status factor", "Psychosocial status factor" and "Health condition factor".

Also, research results encourage thinking of the need of further research of this complex problem area.

That specifically relates to development of bioethical research models on principles of complementarity and supportiveness, and also to development of the new shapes of interdisciplinary communication within which it is necessary to pay attention to the role of different professions which deal with prevention of mental and physical health, education, therapy, palliative protection and rehabilitation. Preventive work activity of somatopedies/ somatopedy-therapists is of crucial importance. Namely, in modern researches, approaches and interpretations of deep and human ecology, the health of an individual is interpreted as existential value and economic category. Existential anxiety, i.e. in a certain way difficulty, is that subjective psycho emotional experience which is manifested in existential difficulties of a subject in somatopsychological functions, sometimes even bellow actual conscience in relation of own body to surroundings. Within that frame, preventive activity of somatopedy, somatopedy therapist is related to encouragement of different sensomotoric, kinesthetic, postural and visceral experiences, on basis of which, changes in conscience of subjects and achievement of new levels of, what is in western literature called "wellbeing" (feeling of comfort, prosperity, sobriety; level of belief in own abilities, success and value), are caused.

\section{REFERENCES}

[1] Čulig J. Racionalna farmakoterapija. Medix 2004; 53: 126-8.

[2] Tomek-Roksandić S, Perko G, Mihok D, Puljak A, Radašević H, Čulig J, Ljubičić M. Živjeti zdravo aktivno starenje. Centar za gerontologiju zavoda za javno zdravstvo grada Zagreba, Zagreb 2003.

[3] Despot-Lučanin J. Iskustvo starenja. Naklada slap, Jastrebarsko 2003.

[4] Kaplan GA, Strawbridge WJ, Camacho TI, Cohen RD. Factors associated with change in physical functioning in the erderly: a 6-year prospective study. Journal of Aging and Health 1989; 5 (1): 140-53.

http://dx.doi.org/10.1177/089826439300500107 
[5] Stawbridge WJ, Camacho T, Cohen RD, Kaplan GA. Gender differences in factors associated with change in physical functioning in old age: a 6-year longitudinal study. The gerontologist 1993; 33 (5): 603-609. http://dx.doi.org/10.1093/geront/33.5.603

[6] Idler EL, KasI SV. (Self-ratings of health: do they also predict change in functional ability? Journal of gerontology: Social Sciences 2005; 48(6): S289-S300.

[7] Fiedler MM, Peres KG. Functional status and associated factors among the elderly in southern Brazilian city: a population-based study. Cad Saude Publica 2008; 24(2): 409-15.

[8] Folstein M, Folstein SM, McHugh PR. Mini Mental State. A practical method for grading the cognitive state of patients for the clinician. Psych Res 1975; 12: 189-98. http://dx.doi.org/10.1016/0022-3956(75)90026-6

[9] Janša J. Ocenjevanje funkcijskega stanja z Brathel indeksom dnevnih aktivnosti. U: Zbornik radova XIV dnevi rehabilitacijske medicine, Ocjenjivanje izida $v$ medicinski rehabilitaciji, ur. H.Burger, N. Goljar i Č Marinček. Ljubljana: Inštitut Republike Slovenije za rehabilitacijo 2003; 51-59.

[10] Zung WWK. A Self Rating Depression Scale, Archives of General Psychiatry 1965; 12: 63-70. http://dx.doi.org/10.1001/archpsyc.1965.01720310065008

[11] Prstačić M. Predavanja iz predmeta Kreativna terapija na postdiplomskom studiju, Edukacijsko rehabilitacijski fakultet, Univerzitet u Tuzli 2003.

[12] Jakovljević D. Nezaposleni u Hrvatskoj: Povezanost socijalne podrške i psihičkog zdravlja. Zagreb: Diplomski rad, Filozofski fakultet 2004.

[13] Kennedy, Gary J, Howard R, Kelman, Cynthia T. The Emergence of Depressive Symptoms in Late Life: The Importance of Declining Health and Increasing Disability. Journal of Community Health 1990;15: 93-104. http://dx.doi.org/10.1007/BF01321314

[14] Roberts RE, Kaplan GA, Shema SJ, Strawbridge WJ. Prevalence and Correlates of Depression in An Aging Cohort: The Alameda County Study". Journal of Gerontology 1997; 52B: S252-S258.

http://dx.doi.org/10.1093/geronb/52B.5.S252
[15] Jay TR, Noh S. Physical Disability and Depression: A Longitudinal Analysis. Journal of Health and Social Behavior 1988; 29: 23-37. http://dx.doi.org/10.2307/2137178

[16] Yang Y, George LK. Functional Disability, Disability Transitions, and Depressive Symptoms in Late Life. Journal of Aging and Health 2005; 17: 263-92. http://dx.doi.org/10.1177/0898264305276295

[17] Yang Y. How Does Functional Disability Affect Depressive Symptoms in Late Life? The Role of Perceived Social Support and Psychological Resources. University of Chicago: Journal of Health and Social Behavior 2006; Vol 47: 355-72.

http://dx.doi.org/10.1177/002214650604700404

[18] Alexopoulos GS, Meyers BS, Young RC, et al. Vascular depression hypothesis. Arch Gen Psychiatry 1997; 54: 91522

http://dx.doi.org/10.1001/archpsyc.1997.01830220033006

[19] Knurowski T, Lazić D, van Dijk JP, Madarasova-Geckova A, Tobiasz-Adamczyk B, van den Heuvel WJA. Dimensions of health among the elderly in Poland and Croatia. The Netherlands: University of Groningen 2004.

[20] Shadbolt B, Barresi J, Craft P. Self-rated health as a predictor of survival among patients with advanced cancer. Journal of Clinical Oncology 2002; 20(10): 2514-19. http://dx.doi.org/10.1200/JCO.2002.08.060

[21] Cott CA, Gignac MAM, Badley EM. Determinants of self rated health for Canadians with chronic disease and disability. J Epidemiol Community Health 1999; 53: 731-36. http://dx.doi.org/10.1136/jech.53.11.731

[22] Damian J, Ruigomez A, Pastor V, Martin-Moreno JM. Determinants of self assessed health among Spanish older people living at home. J Epidemiol Community Health 1999; 53: 412-16. http://dx.doi.org/10.1136/jech.53.7.412

[23] Jang Y, Chiriboga DA, Herrera JR, Branch LG. Self-rating of poor health: A Comparison of Cuban elders in Havana and Miami. J Cross Cult Gerontol 2009; 24: 181-91. http://dx.doi.org/10.1007/s10823-009-9094-x

[24] Haseen F, Adhikari R, Soonthorndhada K. Self-assessed health among Thai elderly. BMC Geriatrics 2010; Vol 10.

\section{DOI: http://dx.doi.org/10.6000/2292-2598.2013.01.01.3}

(C) 2013 Edina et al.; Licensee Lifescience Global.

This is an open access article licensed under the terms of the Creative Commons Attribution Non-Commercial License (http://creativecommons.org/licenses/by-nc/3.0/) which permits unrestricted, non-commercial use, distribution and reproduction in any medium, provided the work is properly cited. 